\title{
Effect of Health Education Via Mobile Application in Promoting Quality of Life Among Asthmatic Schoolchildren in Urban Malaysia: A Quasi-Experimental Study
}

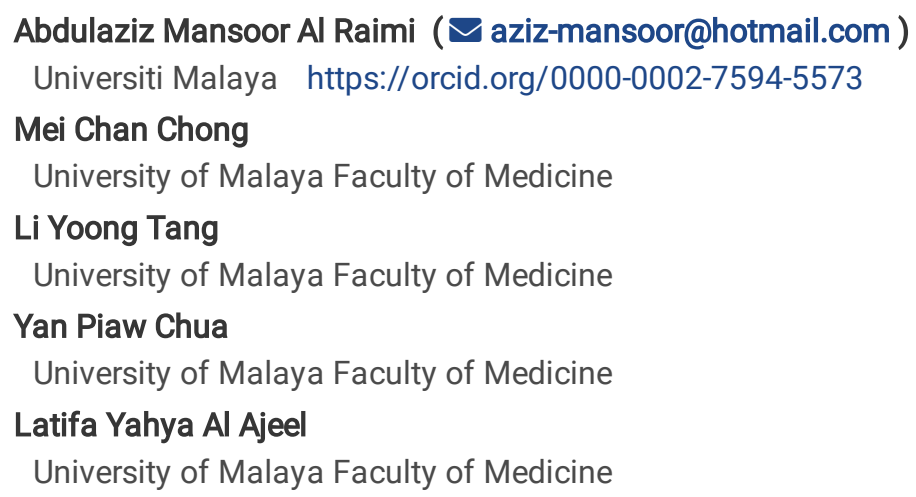

Research Article

Keywords: Asthma, QoL, Health education, Mobile application, COVID-19

Posted Date: June 30th, 2021

DOI: https://doi.org/10.21203/rs.3.rs-340152/v4

License: 두 (i) This work is licensed under a Creative Commons Attribution 4.0 International License. Read Full License 


\section{Abstract}

BACKGROUND: Bronchial asthma among children is a common chronic disease which may have impact on quality of life. Health education is one of the strategy to improve knowledge and quality of life.

OBJECTIVE: The study aims to assess the effect of health education via mobile application (app) in promoting quality of life among schoolchildren with asthma in urban Malaysia.

METHODS: A quasi-experimental, pre- and post-intervention design was used in this study during the period September 2016 until April 2017 involving a total of 214 students, randomly assigned into two groups (intervention group and control group). The control group received face-to-face health education while the experimental group received health education via a mobile application.

RESULTS: The findings showed that the total score of quality of life (QoL) has improved from a mean total score at pre-intervention (5.31 \pm 1.27$)$ to post-intervention (5.66 \pm 1.28$)$ for the control group, compared with the experimental group with a mean total score of QoL at pre-intervention (5.01 \pm 1.36 ) and post-intervention (5.85 \pm 1.29$)$. A comparison between the experimental and control groups using an independent t-test showed statistically significant differences in their mean QoL scores. The effect of health education via mobile application showed a statistically significant improvement in the mean QoL score from pre- to post-intervention $[F(1,288)=57.46, p=$ $<0.01]$.

CONCLUSION: The use of mobile technology in health education improved QoL as compared to the traditional methods of face-to-face lecture and/or handbooks among schoolchildren with asthma. Thus, educational modules using mobile applications do improve QoL.

\section{Background}

Asthma is a chronic inflammatory disease of the airways caused by bronchial hyperresponsiveness to a variety of stimuli which leads to the obstruction of airflow that can be reversible by self or by treatment (1). It is one of the most chronic illnesses prevalent among adolescents in industrialized societies (2).

The global prevalence of asthma varies from one country to another and ranges from $5 \%$ to $20 \%$ or even more (3). Among asthmatic patients, $3 \%$ to $10 \%$ suffer from severe asthma. Moreover, $10 \%$ to $25 \%$ of asthmatic patients in a speciality clinic have severe asthma (4). Asthma is gradually becoming a burden among children in Malaysia and it has been categorized as one of the most influencing factors affecting the quality of life of children and their parents (5).

Poorly managed effects of asthma can affect children's quality of life. Studies show that low quality of life increases future emergency room visits relating to asthma, which indicates inadequate control of asthma (6). Asthma can affect the quality of life because the disease or treatment process could change the physical, psychological, and social functions (7) of not only asthmatic children but also their parents (8).

Education is the main key to improving patient knowledge, skill, and compliance, especially for patients with poor knowledge and compliance (9). So, improving the knowledge of schoolchildren about asthma leads to reducing distress and severity and thus improving the quality of life; and learning from this, the nursing staff will have guidance in developing better health services to improve the quality of life of children (10).

In the recent COVID-19 pandemic, research has found that both children and adults with asthma tended to be more vulnerable to the disease, although there was no major sex disparity (11). The existing literature agrees on the wide range of impact of school closure, ranging from not beneficial to transmission declines to more significant consequences. School closure incurs high economic costs and possible damages (12). At the same time, being indoors could make children more vulnerable to indoor conditions that may worsen asthma, including secondary sensitivity to cigarette smoke and occupational allergens such as moulds, rodents, and roaches (13). Despite the lack of evidence, experts strongly agree that all children and adolescents with asthma stay on their asthma treatment plan throughout the COVID-19 outbreak (14).

Smartphones are used by about $50 \%$ of adolescents aged $12-17$ years old and $75 \%$ of adults aged $30-49$ years old. Hence, an intervention via mobile health (mHealth) applications is a great alternative during this time, directed at assisting adolescents with chronic asthma as they shift to take on more responsibility for their asthma treatment (15). Unfortunately, the literature on the usage of smartphone technology in patient care is lacking. Most healthcare application users focus on monitoring their condition rather than 
improving their knowledge or management of the disease (16). However, there are several studies available evaluating the effectiveness of smartphone usage in children's health education and how health education can improve their QoL, especially during the COVID-19 era (9).

The present study is part of a research project titled Developing Children Asthma Program (CAP) that promotes health outcomes among schoolchildren in Malaysia. This study aims to assess the effect of health education via mobile application in promoting quality of life among asthmatic schoolchildren in urban Malaysia.

\section{Methods \\ Design}

This is a quantitative study in the form of a quasi-experimental, pre-test and post-test, non-equivalent control group design. The quasiexperimental study is a research design used to evaluate interventions that do not involve randomization $(17,18)$. The researcher chose this design because of the inability to manipulate or control the environment and the use of non-randomized subjects. Randomization is difficult in educational studies; and since this study took place in a group environment which included schoolchildren in classrooms, the samples could not be individually monitored by the researcher (19). Data collection was conducted from September 2016 until April 2017.This study design would also assess the differences between the pre-test results of the experimental and control groups, variations between pre-test and post-test results, and variations between the post-test results of the experimental and control groups that are compatible with the particular objectives of the current study.

As shown in Figure 1, the participants from the selected schools were randomly divided into two groups. The schoolchildren in the experimental group were from different schools than those in the control group. In this study, the control group used only traditional methods of education (face-to-face) while the experimental group received education via a mobile application. In addition, there employed 'controlled before and after', a control population with similar characteristics to the study population who were expected to undergo similar changes that occurred to the study population (20). The outcome measures were assessed after 3 months, postintervention, for both groups. We randomly chose 6 schools located in the city of Petaling Jaya in the state of Selangor, Malaysia. We then randomly assigned the schools into 2 groups, 3 schools for the experimental group and 3 schools for the control group, from which we recruited schoolchildren who met the inclusion criteria. According to Brydges (21), the sample size required for group differences research to achieve $80 \%$ statistical power using a power analysis with $\alpha=.05$ (two-tailed) is 107 per group; hence, a total of 214 schoolchildren were involved in this study. The inclusion criteria were students who have had an asthma diagnosis, students showing asthma symptoms in the last 12 months, students who have a smartphone, and students who speak either English or Malay. The exclusion criteria were students who have other significant comorbidities and students who refused to participate in the study.

\section{Research Phases}

This research was conducted in four phases. The first phase was constructing the health education program about bronchial asthma, 'Asthma Care Program ${ }^{\circledR}$ ' and developing the mobile application, 'MemahamiAsma ${ }^{\circledR}$ ' that began with an extensive literature review. The second phase was conducting a quasi-experimental study which first used a survey to identify eligible participants according to the inclusion criteria, followed by a pre-intervention assessment. In the third phase, the control group attended face-to-face health education regarding asthma and the experimental group attended online learning for 1 hour, followed by mobile application-based learning over the next 3 months. The last phase was the follow-up three months after the health education interventions for the control and experimental groups using a self-administered questionnaire, similar to that at pre-health education intervention, to assess the schoolchildren' QoL.

\section{Study Instruments}

\section{Demographical Data}

This instrument was developed by the researcher based on previous studies $(3,22-25)$. This data consists of the schoolchildren's general information, their demographical status, gender, age, race, and family history of asthma. This questionnaire aims to evaluate the correlation between demographic factors and QoL level among asthmatic schoolchildren.

\section{Quality of Life Questionnaire}


The questionnaire used to measure the quality of life of the schoolchildren was adopted from the Pediatric Asthma Quality of Life Questionnaire (PAQOLQ) which was designed and validated by Juniper et al. (1996). This instrument contains 23 questions in three domains (symptoms, activity limitations, and emotional function). The schoolchildren were asked to recall their experiences during the previous week and to respond to each question on a 7-point scale.

\section{Health Education Intervention Tools}

\section{Educational pamphlet 'Asthma Care Program ${ }^{\circledR}$}

Asthma Care Program ${ }^{\circledR}$ is a children's asthma pamphlet developed by the researcher in both English and Malay based on the literature review and the evaluation by a panel of experts. This tool was designed to be colourful, entertaining, educational, and developmentally appropriate as well as diverse regarding gender, race, and culture. The content of the pamphlet includes the anatomy and physiology of the lungs and the management and prevention of asthma. This pamphlet was distributed to the control group (Figure 2).

\section{Mobile application 'MemahamiAsma®'}

The asthma mobile application called MemahamiAsma ${ }^{\circledR}$ was developed by an android developer in cooperation with the research team in both English and Malay to support children with asthma in their daily care needs. The mobile application is an electronic alternative for the pamphlet and contains all data on asthma.

\section{Application design process}

The design process of MemahamiAsma ${ }^{\circledR}$ is based on the goal-directed design (GDD) (26) and Health Literacy Online's six main strategies (27). To simplify the process of the design, modifications were made to both aforementioned methods by dividing the design process into four stages covering the two phases of development and deployment. Figure 3 depicts the design process of MemahamiAsma®.

\section{User manual}

'Understanding Asthma' or MemahamiAsma $\AA^{\circledR}$ is a simple-to-use and straight-to-the-point android application for high school students in Malaysia. The application is developed in both English and Malay as shown in Figure 4.

On the first page, the user will see the login page. They have to enter their login ID and password. The user then has to choose their preferred language, either English or Malay. After choosing their language, the user will be greeted by a tabbed page, populated with INFO tabs (information on asthma) and FAQ tabs (frequently asked questions about asthma). The last page is the contacts page; if advanced knowledge and information regarding asthma or asthma research or any other related events or activities are needed, this page provides the user with the contacts to societies related to asthma, which are the Malaysian Thoracic Society (MTS) and the Malaysian Society of Allergy and Immunology (MSAI).

\section{Data Collection}

Data collection was carried out for both groups separately to avoid contamination of data. The samples were randomly divided into two groups, the experimental group and the control group. The control group attended a face-to-face lecture about asthma and received Asthma Care Program ${ }^{\circledR}$, the educational pamphlet. The experimental group first attended online learning for 1 hour, followed by mobile app-based learning over the next 3 months. The frequency and duration of use of the mobile application were flexible and according to the user's preference.

\section{Data Analysis}

Data were analyzed using the Social Package Statistical Software (SPSS) version 22. Descriptive and inferential statistics were used to summarize the demographics of the schoolchildren and their level of QoL. Quantitative data included the calculation of mean and standard deviation. The associations between categories were determined using the Chi-squared test and the difference in mean at pretest and post-test was analysed using the Split-plot ANOVA. The statistical significance is fixed at $p<0.05$. 


\section{Results}

\section{Profile of the Sample}

A total of 214 schoolchildren participated in this study, with 107 students in the control group and another 107 students in the experimental group. The data show that female students made up more than half of all students in both control and experimental groups with $(n=55,51.4 \%)$ and $(n=63,58.9 \%)$ respectively. Also, there were more students aged 15-16 years old than 13-14 years old in the control group ( $n=59,55.1 \%)$ and the experimental group ( $n=62,57.9 \%)$. Regarding ethnicity, around two-third of the students are Malay, $(n=73,68.2 \%)$ in the control group and $(n=72,67.3 \%)$ in the experimental group; Indian, $(n=25,23.4 \%)$ in the control group and $(n=18,16.8 \%)$ in the experimental group; and Chinese, $(n=9,8.2 \%)$ in the control group and $(n=17,15.9 \%)$ in the experimental group.

In addition, the results showed that the age of more than half of the students in the control group $(n=60,56 \%)$ and the experimental group ( $n=55,51 \%$ ) when they had first been diagnosed with asthma is between $0-6$ years old, while around half of them from both the control and experimental groups, $(n=45,42 \%)$ and $(n=48,45 \%)$ respectively, were diagnosed with asthma in a hospital (Table 1).

\section{Relationship Between Demographic Characteristics and QoL of the Control and Experimental Groups at Pre-Intervention}

The data in Table 2 show that the quality of life level of 'No Impairment' was highest in the control group whereas 'Moderate Impairment' was highest in the experimental group. In the control group, 'No Impairment' was highest for the following factors: 15 - 16 years old $(n=34,58.6 \%)$, Malay $(n=43,58.9 \%)$, and male students $(n=35,67.2 \%)$. Meanwhile, in the experimental group, 'Moderate Impairment' was highest for the following factors: $14-15$ years old $(n=29,48.8 \%)$, Malay $(n=45,62.5 \%)$, and female students $(n=39,61.9 \%)$.

However, there was no statistically significant difference $(p<0.05)$ in the quality of life level throughout, so univariate logistic model analysis was not conducted in this situation. Thus, the demographic variables do not influence the dependent variable, QoL.

\section{Total QoL Level and QoL Domains}

As can be seen from Table 3, data show a slight increase in the mean total quality of life score in the control group from pre-intervention $(5.31 \pm 1.27)$ to post-intervention $(5.66 \pm 1.28)$. Meanwhile, the experimental group experienced a significant increase in the mean total quality of life score from pre-intervention $(5.01 \pm 1.36)$ to post-intervention $(5.85 \pm 1.29)$. Regarding the QoL domains: in the control group, symptoms functioning had the highest score at pre-intervention $(4.99 \pm 1.39)$ and post-intervention $(5.92 \pm 1.09)$, whereas activity limitation had the lowest score at pre-intervention (5.19 \pm 1.33$)$ and emotional functioning at post-intervention (5.48 \pm 1.39$)$. Furthermore, in the experimental group, symptoms functioning had the highest score at pre- and post-intervention, $(5.13 \pm 1.53)$ and $(6.09 \pm 1.26)$ respectively, whereas emotional functioning had the lowest score at pre- and post-intervention, $(4.9 \pm 1.27)$ and $(5.57 \pm 1.41)$ respectively.

A comparison between the experimental and control groups using an independent t-test showed statistically significant differences in the mean quality of life scores between them.

\section{Effectiveness of Health Education via Mobile Application}

This research question was answered using inferential statistics. Generalized Linear Model (GLM), Split-Plot ANOVA (SPANOVA) was used to examine the significant difference in the mean score of QoL (improvement) among the schoolchildren with asthma between the experimental and control groups.

Table 4 presents the summary of SPANOVA results that includes within-subjects effects (pre- and post-intervention score of QoL level) and between-subject effects (the experimental and control groups). The null hypothesis is rejected, and the effect of the mobile application is significantly effective in improving the QoL level of the students. The profile plot in Figure 5 indicates that the QoL level of the experimental group increased from pre-test to post-test.

\section{Discussion}

The present study reveals that poor asthma control will affect the daily life of asthmatic schoolchildren and their adaptation to the illness in several aspects of life such as the physical, emotional, psychological, and social during the COVID-19 era. These complications 
of asthma may lead them to have a high risk of school absenteeism (28). In the USA, the National Interview Survey mentioned that children with asthma have 3 times more school absentees and have more risk of learning disability compared with normal children (29).

During the recent COVID-19 pandemic, parents of children with asthma have voiced their worries regarding asthma management during this pandemic. They may have even improved their attention to medicine for their children (13). In the UK, one research found a 76\% decline in emergency visits for asthma of all severities during the COVID-19 pandemic. It is doubtful that this drop in hospital admissions can be compensated solely by parents who treat mild attacks at home, but the reasons remain unclear for what is obviously a relevant improvement. Lockdowns to avoid the spread of conventional respiratory viruses and diminished exposure to outdoor allergens may be factors. (30).

In this study, the emotional sub-scale contributed the most to the schoolchildren's QoL impairment in both groups, and this is consistent with previous studies which revealed that adolescents with persistent asthma had common emotional symptoms related to asthma due to increased asthma morbidity, healthcare use, and school absenteeism. On the other hand, it would mean that adolescents with high morbidity from asthma have a high risk of poorer QoL. Therefore, emotional QoL should be included in the assessment of adolescents with asthma (31). Another study conducted in Saudi Arabia assessed the influence of attitude on asthma severity and quality of life among asthmatic children. Their levels of quality of life also showed a higher score in the emotional domain compared to the physical (32).

Furthermore, in the USA, there reported slightly poorer emotional processing in Hispanic children in comparison to the non-Hispanic White and African American children. The emotional sub-scale explored how often children feel upset, anxious, worried, or distressed because of their asthma and how often they are frightened by an asthma attack (33). Poor asthma control among children is a manifested public health problem. It causes respiratory health problems, limits physical activity, and leads to missed school days and also parental work absenteeism (34). Different studies found that physical functioning and vitality are the typical measurements most impaired by asthma, and the explanation for this contradicts our study conducted among schoolchildren with mild asthma, as these other studies were performed among those with moderate to extreme illness, where the study population had weak physical functioning (35).

On the other hand, the present study reveals the effect of a mobile application in promoting quality of life among asthmatic schoolchildren, the result of this study is similar to the previous systemic review which aimed to assess the effect of a mobile application to support adult patients with asthma; the result demonstrated that both patients with asthma and healthcare providers had improved quality of life (36). Another study in the USA that assessed a mobile technology-based educational program on schoolchildren to improve asthma self-management and outcomes found that parents of the schoolchildren demonstrated significant improvements in their asthma caregiver-related quality of life (37).

It is therefore concluded that the use of mobile technology in health education has a good impact in improving the QoL of schoolchildren with asthma as compared to other traditional methods like face-to-face lecture or handbooks. This finding agrees with those of other research which revealed that the mobile health (mHealth) initiatives have an impact on improving chronic disease conditions (38). In another systemic review conducted by Majeed-Ariss, Baildam (39), it was explained that mobile applications have good benefits to adolescents since mobile technologies and featuring software applications are now widely used by this age group either for social networking or for gaming purposes. Hence, mobile applications could be used for healthcare educational purposes or as healthcare support.

As recommended, there is a need to assess efficacy and cost-effectiveness for using information technology to improve asthma treatment and knowledge, which must be reinforced by randomized trials (40). The outcomes of such studies are urgently needed. The simplicity with which these strategies integrate into our everyday lives and the meaning of continuous chronic care indicates that these imaginative and innovative approaches may be a beneficial addition to successful clinical practice.

\section{Conclusion}

In this quasi-experimental research, there concluded the finding - the use of mobile technology in health education improves QoL levels of schoolchildren with asthma, compared with other traditional methods like face-to-face lecture or handbooks, especially during the COVID-19 era.

\section{Limitations And Recommendations}


The first limitation identified in this study is its quasi-experimental design. Due to the absence of randomization, there is likely the presence of selection bias. There realized that self-reported questionnaires could lead to introducing bias to the results of the study, as it might not describe the true condition of the participants; they might rate higher or lower than the true condition. Other limitations include the probability of some participants failing to install the application, of which the reason is undetermined (might have occurred during registration). Also, we do not know if any of the schoolchildren in the control group had somehow accessed or downloaded the application. Similarly, we did not account for the use of other asthma mobile health software by the participants.

In this study, data on the patients' perception of illness, self-motivation, and approaches to self-management were not collected. Therefore, it is recommended for future research to investigate further regarding symptoms experienced by patients by gathering information on their illness perceptions, self-motivation, self-efficacy, and self-management strategies. Data retrieved can be integrated into psycho-educational programs to promote behaviour change, hence improving the patients' self-management skills.

\section{Practical Value}

With sufficient basic knowledge regarding asthma, especially on adhering to proper medication, the QoL of asthmatic schoolchildren would eventually improve. Thus, it is important for school nurses to identify and implement different strategies regarding asthma medication/treatment.

Health education via mobile applications is considered a great innovation in asthmatic students' education, or as a supplement to conventional learning methods. It is necessary to place health education via mobile applications as a prominent learning strategy for asthmatic students, with careful planning considering all aspects such as the age of the students, lecturers, learning facilitators, and technological use to achieve learning outcomes, which are to decrease symptoms and prevent complications. Therefore, health education via mobile applications is suggested as an effective learning strategy in promoting knowledge and QoL of asthmatic students within their existing education in schools throughout Malaysia.

\section{Declarations}

\section{ETHICAL APPROVAL}

Permission was granted by the Ministry of Education, the Ministry of Health, and the respective schools and principals. This study was registered under the Medical Research Committee, University Malaya Medical Centre, MRECID. NO: 2016112-4501. Also, this study is registered with the Australian New Zealand Clinical Trials Registry (ANZCTR) under Trial ID: ACTRN12614300582550.

\section{ACKNOWLEDGEMENT}

We would like to thank the University of Malaya Research Grant for their funding of this study under the scheme, Postgraduate Research Grant (PPP) No. PG196-2015A. We would also like to thank Dr Mohammed Al-Mekhlafi and Dr Mohammed A. Al-Sharafi for their help and advice.

\section{CONFLICTS OF INTEREST/COMPETING INTERESTS:}

The authors declare that they have no conflicts of interest.

\section{References}

1. Fajt ML, Wenzel SE. Development of New Therapies for Severe Asthma. Allergy Asthma Immunol Res. 2017;9(1):3-14.

2. Alquran A, Lambert KA, Farouque A, Holland A, Davies J, Lampugnani ER, et al. Smartphone Applications for Encouraging Asthma Self-Management in Adolescents: A Systematic Review. International journal of environmental research and public health. 2018;15(11):2403.

3. Shimwela M, Mwita J, Mwandri M, Rwegerera G, Mashalla Y, Mugusi F. Asthma prevalence, knowledge, and perceptions among secondary school pupils in rural and urban coastal districts in Tanzania. BMC Public Health. 2014;14(1):387. 
4. Kim S-H, Moon JY, Lee JH, Ban G-Y, Kim S, Kim M-A, et al. Perceptions of Severe Asthma and Asthma-COPD Overlap Syndrome Among Specialists: A Questionnaire Survey. Allergy Asthma Immunol Res. 2018;10(3):225-35.

5. Fadzil A, Norzila MZ. Parental asthma knowledge. Med J Malaysia. 2002;57(4):474-81.

6. Ahmad N, Ismail A, Sulong S, Rahman RA. Determinant for Quality of Life among Childhood Asthma in Malaysia: A Cross Sectional Study. International Medical Journal. 2017;24(2):195-9.

7. Patrick DL, Bergner M. Measurement of health status in the 1990s. Annual review of public health. 1990;11:165-83.

8. Stelmach I, Podlecka D, Smejda K, Majak P, Jerzyńska J, Stelmach R, et al. Pediatric Asthma Caregiver's Quality of Life Questionnaire is a useful tool for monitoring asthma in children. Quality of Life Research. 2012;21(9):1639-42.

9. Choi JY, Cho Chung HI. Effect of an individualised education programme on asthma control, inhaler use skill, asthma knowledge and health-related quality of life among poorly compliant Korean adult patients with asthma. Journal of clinical nursing. 2011;20(12):119-26.

10. Yang BH, Chen YC, Chiang BL, Chang YC. Effects of nursing instruction on asthma knowledge and quality of life in schoolchildren with asthma. The journal of nursing research : JNR. 2005;13(3):174-83.

11. Pei Y, Liu W, Bilal Masokano I, Li F, Xie S, Zhou G, et al. COVID-19: Children Comparison with Adults Based on the Latest Data. Available at SSRN 3550063. 2020.

12. Viner R, Russell S, Croker H, Packer J, Ward J, Stansfield C, et al. School Closure and Management Practices during Coronavirus Outbreaks including COVID-19: A Rapid Narrative Systematic Review. Available at SSRN 3556648. 2020.

13. Oreskovic NM, Kinane TB, Aryee E, Kuhlthau KA, Perrin JM. The Unexpected Risks of COVID-19 on Asthma Control in Children. The Journal of Allergy and Clinical Immunology: In Practice. 2020.

14. Licari A, Votto M, Brambilla I, Castagnoli R, Piccotti E, Olcese R, et al. Allergy and asthma in children and adolescents during the COVID outbreak: What we know and how we could prevent allergy and asthma flares. Allergy. 2020;n/a(n/a).

15. Fedele DA, McConville A, Graham Thomas J, McQuaid EL, Janicke DM, Turner EM, et al. Applying Interactive Mobile health to Asthma Care in Teens (AIM2ACT): Development and design of a randomized controlled trial. Contemporary Clinical Trials. 2018;64:2307 .

16. Haze KA, Lynaugh J. Building patient relationships: a smartphone application supporting communication between teenagers with asthma and the RN care coordinator. Computers, informatics, nursing : CIN. 2013;31(6):266-71; quiz 72-3.

17. Houser J. Nursing research: Reading, using and creating evidence: Jones \& Bartlett Learning; 2016.

18. Harris AD, McGregor JC, Perencevich EN, Furuno JP, Zhu J, Peterson DE, et al. The use and interpretation of quasi-experimental studies in medical informatics. Journal Of The American Medical Informatics Association: JAMIA. 2006;13(1):16-23.

19. Stone R, Cooper S, Cant R. The value of peer learning in undergraduate nursing education: A systematic review. ISRN nursing. $2013 ; 2013$.

20. Grimshaw J, Campbell M, Eccles M, Steen N. Experimental and quasi-experimental designs for evaluating guideline implementation strategies. Fam Pract. 2000;17 Suppl 1:S11-6.

21. Brydges CR. Effect Size Guidelines, Sample Size Calculations, and Statistical Power in Gerontology. Innovation in Aging. 2019;3(4).

22. Solis Soto M, Patino A, Nowak D, Radon K. Prevalence of asthma, rhinitis and eczema symptoms in rural and urban school-aged children from Oropeza Province - Bolivia: a cross-sectional study. BMC Pulmonary Medicine. 2014;14(1):40.

23. Mehravar F, Rafiee S, Bazrafshan B, Khodadost M. Prevalence of asthma symptoms in Golestan schoolchildren aged 6-7 and 13-14 years in Northeast Iran. Frontiers of Medicine. 2016;10(3):345-50. 
24. Narayana PP, Prasanna MP, Narahari S, Guruprasad AM. Prevalence of asthma in school children in rural India. Annals of thoracic medicine. 2010;5(2):118.

25. Quah BS, Razak AR, Hassan MH. Prevalence of asthma, rhinitis and eczema among schoolchildren in Kelantan, Malaysia. Acta paediatrica Japonica; Overseas edition. 1997;39(3):329-35.

26. Duan H, Wang Z, Ji Y, Ma L, Liu F, Chi M, et al. Using goal-directed design to create a mobile health app to improve patient compliance with hypertension self-management: development and deployment. JMIR mHealth and uHealth. 2020;8(2):e14466.

27. Hou S-I. Health literacy online: A guide to writing and designing easy-to-use health web sites. Sage Publications Sage CA: Los Angeles, CA; 2012.

28. Anwar H, Hassan N, Jaffer N, Al-Sadri E. Asthma Knowledge among Asthmatic School Students. Oman Medical Journal. 2008;23(2):90-5.

29. Cicutto L, Gleason M, Szefler SJ. Establishing school-centered asthma programs. Journal of Allergy and Clinical Immunology. 2014;134(6):1223-30.

30. Kenyon CC, Hill DA, Henrickson SE, Bryant-Stephens TC, Zorc JJ. Initial effects of the COVID-19 pandemic on pediatric asthma emergency department utilization. The Journal of Allergy and Clinical Immunology: In Practice. 2020;8(8):2774-6.e1.

31. Cerdan NS, Alpert PT, Moonie S, Cyrkiel D, Rue S. Asthma severity in children and the quality of life of their parents. Applied Nursing Research. 2012;25(3):131-7.

32. Alsamghan AS, Awadalla NJ, Mohamad YA, Hassan AM. Influence of altitude on pediatric asthma severity and quality of life in southwestern Saudi Arabia. Egyptian Journal of Chest Diseases and Tuberculosis. 2016;65(3):555-61.

33. Horner SD, Brown SA, Walker VG. Is rural school-aged children's quality of life affected by their responses to asthma? Journal of pediatric nursing. 2012;27(5):491-9.

34. Gerald LB, Gerald JK, Zhang B, McClure LA, Bailey WC, Harrington KF. Can a school-based hand hygiene program reduce asthma exacerbations among elementary school children? Journal of Allergy and Clinical Immunology. 2012;130(6):1317-24.

35. Sararaks S, Rugayah B, Azman A, Karuthan C, Low L. Quality of Life-How Do Malaysian Asthmatics Fare? Medical Journal of Malaysia. 2001;56(3):350-8.

36. Hui CY, Walton R, McKinstry B, Jackson T, Parker R, Pinnock H. The use of mobile applications to support self-management for people with asthma: a systematic review of controlled studies to identify features associated with clinical effectiveness and adherence. J Am Med Inform Assoc. 2017;24(3):619-32.

37. Warren CM, Dyer A, Blumenstock J, Gupta RS. Leveraging Mobile Technology in a School-Based Participatory Asthma Intervention: Findings From the Student Media-Based Asthma Research Team (SMART) Study. American Journal of Health Education. 2016;47(2):59-70.

38. Everhart RS, Heron KE, Leibach GG, Miadich SA. Developing a Mobile Health Intervention for Low-Income, Urban Caregivers of Children with Asthma: A Pilot Study. Pediatric Allergy, Immunology \& Pulmonology. 2017;30(4):252-6.

39. Majeed-Ariss R, Baildam E, Campbell M, Chieng A, Fallon D, Hall A, et al. Apps and Adolescents: A Systematic Review of Adolescents' Use of Mobile Phone and Tablet Apps That Support Personal Management of Their Chronic or Long-Term Physical Conditions. Journal of medical Internet research. 2015;17(12):e287.

40. Mosnaim GS, Powell LH, Rathkopf M. A Review of Published Studies Using Interactive Internet Tools or Mobile Devices to Improve Asthma Knowledge or Health Outcomes. Pediatric Allergy, Immunology \& Pulmonology. 2012;25(2):55-63.

\section{Tables}

Table 1: Baseline socio-demographic characteristics $(\mathrm{N}=290)$ 


\begin{tabular}{|c|c|c|c|c|}
\hline Variables & Control Group & Experimental Group & $x^{2}$ & $P$ \\
\hline n (\%) & n (\%) & & & \\
\hline Gender & & & .086 & .769 \\
\hline Male & $52(48.6)$ & $44(41.1)$ & & \\
\hline Female & $55(51.4)$ & $63(58.9)$ & & \\
\hline Age & & & & \\
\hline 13-14 & $48(44.9)$ & $45(42.1)$ & 1.476 & .478 \\
\hline 15-16 & $59(55.1)$ & $62(57.9)$ & & \\
\hline Ethnic & & & 6.682 & .083 \\
\hline Malay & $73(68.2)$ & $72(67.3)$ & & \\
\hline Indian & $25(23.4)$ & $18(16.8)$ & & \\
\hline Chinese & $9(8.2)$ & $17(15.9)$ & & \\
\hline Age at asthma diagnosis & & & 5.454 & 0.708 \\
\hline 0 - 6 years old & $60(56)$ & $55(51)$ & & \\
\hline 6 - 13 years old & $47(44)$ & $52(49)$ & & \\
\hline Where was your asthma first diagnosed? & & & 264.981 & $<0.001$ \\
\hline Hospital & $45(42)$ & $48(45)$ & & \\
\hline Clinic & $36(33)$ & $48(45)$ & & \\
\hline Non-specific & $27(25)$ & $11(10)$ & & \\
\hline Total & $107(100)$ & $107(100)$ & & \\
\hline
\end{tabular}

Table 2: Relationship between demographics characteristics and QoL levels at pre-intervention $(\mathrm{n}=107)$

\begin{tabular}{|c|c|c|c|c|c|c|c|c|c|c|}
\hline \multirow{3}{*}{ Factors } & \multicolumn{4}{|c|}{ Control Group } & \multirow{3}{*}{$\begin{array}{c}\text { Chi- } \\
\text { square } \\
x^{2} \\
P\end{array}$} & \multicolumn{4}{|c|}{ Experimental Group } & \multirow{3}{*}{$\begin{array}{c}\text { Chi- } \\
\text { square } \\
x^{2} \\
P\end{array}$} \\
\hline & \multirow[t]{2}{*}{$\mathrm{N}=107$} & \multicolumn{3}{|c|}{$\begin{array}{c}\text { QoL level } \\
\mathrm{n}(\%)\end{array}$} & & \multirow[t]{2}{*}{$\mathrm{N}=107$} & \multicolumn{3}{|c|}{$\begin{array}{c}\text { QoL level } \\
\text { n (\%) }\end{array}$} & \\
\hline & & $\begin{array}{c}\text { No } \\
\text { impairment }\end{array}$ & $\begin{array}{c}\text { Moderate } \\
\text { impairment }\end{array}$ & $\begin{array}{c}\text { Severe } \\
\text { impairment }\end{array}$ & & & $\begin{array}{c}\text { No } \\
\text { impairment }\end{array}$ & $\begin{array}{c}\text { Moderate } \\
\text { impairment }\end{array}$ & $\begin{array}{c}\text { Severe } \\
\text { impairment }\end{array}$ & \\
\hline Gender & & & & & & & & & & .179 \\
\hline Male & 52 & $35(67.3)$ & $16(30.8)$ & $1(1.9)$ & .177 & 44 & $18(40.9)$ & $26(59.1)$ & $0(0.0)$ & \\
\hline Female & 55 & $30(54.5)$ & $23(41.9)$ & $2(3.6)$ & & 63 & $20(31.7)$ & 39 (61.9) & $4(6.3)$ & \\
\hline Age & & & & & & & & & & .597 \\
\hline $13-14$ & 48 & $31(64.6)$ & $15(31.3)$ & $2(4.2)$ & .376 & 45 & $18(40.0)$ & $26(57.8)$ & $1(2.2)$ & \\
\hline $15-16$ & 59 & $34(58.6)$ & $24(39.7)$ & $1(1.7)$ & & 62 & $20(32.3)$ & 39 (62.9) & $3(4.8)$ & \\
\hline \multicolumn{11}{|l|}{ Ethnic } \\
\hline Malay & 73 & $43(58.9)$ & $27(37)$ & $3(4.1)$ & .685 & 72 & 23 (31.9) & 46 (63.9) & $3(4.2)$ & .717 \\
\hline Indian & 25 & $17(68)$ & $8(32)$ & $0(0.0)$ & & 18 & $8(44.4)$ & $10(55.6)$ & $0(0.0)$ & \\
\hline Chinese & 9 & $5(55.6)$ & $4(44.4)$ & $0(0.0)$ & & 17 & $7(41.2)$ & $9(52.9)$ & $1(5.9)$ & \\
\hline
\end{tabular}

*Significance level at $\mathrm{p}<0.05$

Table 3: Descriptive statistics of QoL domains of experimental and control groups $(n=214)$ 


\begin{tabular}{|c|c|c|c|c|c|c|c|c|c|}
\hline \multirow[t]{3}{*}{ Domains } & \multicolumn{4}{|c|}{$\begin{array}{l}\text { Control Group } \\
\qquad(\mathrm{N}=107)\end{array}$} & \multicolumn{4}{|c|}{$\begin{array}{l}\text { Experimental Group } \\
\qquad(\mathrm{N}=107)\end{array}$} & \multirow{3}{*}{$\begin{array}{c}\text { Between } \\
\text { groups } \\
\text { (Exp. vs. } \\
\text { Con.) } \\
p\end{array}$} \\
\hline & \multicolumn{2}{|c|}{$\begin{array}{l}\text { The mean total of QoL } \\
\qquad \pm \mathrm{SD}\end{array}$} & \multirow{2}{*}{$\begin{array}{c}\text { Diff. } \\
\text { (Post- } \\
\text { Pre) } \\
\text { M土SD }\end{array}$} & \multirow{2}{*}{$\begin{array}{c}\text { Within- } \\
\text { group } \\
\text { Paired } \\
\text { t-test, } \\
p\end{array}$} & \multicolumn{2}{|c|}{$\begin{array}{l}\text { The mean total of QoL } \\
\qquad \mathrm{M} \pm \mathrm{SD}\end{array}$} & \multirow{2}{*}{$\begin{array}{c}\text { Diff. } \\
\text { (Post- } \\
\text { Pre) } \\
\text { M } \pm \text { SD }\end{array}$} & \multirow{2}{*}{$\begin{array}{l}\text { Within- } \\
\text { group } \\
\text { Paired } \\
\text { t-test, } \\
\quad p\end{array}$} & \\
\hline & $\begin{array}{l}\text { Pre-health } \\
\text { education }\end{array}$ & $\begin{array}{l}\text { Post-health } \\
\text { education }\end{array}$ & & & $\begin{array}{l}\text { Pre-health } \\
\text { education }\end{array}$ & $\begin{array}{l}\text { Post-health } \\
\text { education }\end{array}$ & & & \\
\hline $\begin{array}{l}\text { Overall } \\
\text { mean }\end{array}$ & $5.31(1.27)$ & $5.66(1.28)$ & $\begin{array}{c}0.35 \\
(1.25)\end{array}$ & $<0.001$ & $5.01(1.36)$ & $5.85(1.29)$ & $\begin{array}{c}0.84 \\
(1.41)\end{array}$ & $<0.001$ & $<0.001$ \\
\hline $\begin{array}{l}\text { Activity } \\
\text { limitation }\end{array}$ & $5.19(1.33)$ & $5.57(1.43)$ & $\begin{array}{c}0.39 \\
(1.25)\end{array}$ & 0.03 & $5.03(1.56)$ & $5.81(1.48)$ & $\begin{array}{c}0.78 \\
(1.67)\end{array}$ & $<0.001$ & $<0.001$ \\
\hline $\begin{array}{l}\text { Emotional } \\
\text { function }\end{array}$ & 4.99 (1.39) & 5.48 (1.39) & $\begin{array}{c}0.49 \\
(1.60)\end{array}$ & $<0.001$ & $4.9(1.27)$ & $5.57(1.41)$ & $\begin{array}{r}0.67 \\
(1.51)\end{array}$ & $<0.001$ & $<0.001$ \\
\hline Symptoms & $5.44(1.37)$ & $5.92(1.09)$ & $\begin{array}{c}0.49 \\
(1.36)\end{array}$ & $<0.001$ & $5.13(1.53)$ & $6.09(1.26)$ & $\begin{array}{r}0.97 \\
(1.51)\end{array}$ & $<0.001$ & $<0.001$ \\
\hline
\end{tabular}

Note:

Within-group - pre and post comparison within experimental and control groups

Between-group - comparison between experimental and control groups

Table 4: SPANOVA results for effectiveness of health education via mobile app

\begin{tabular}{lccccc}
\hline & Sum of Squares & $\mathrm{df}$ & Mean Square & $\mathrm{F}$ & $\mathrm{p}$ \\
\hline Test & 51.27 & 1 & 51.27 & 57.46 & $<0.01$ \\
Test* Group & 8.69 & 1 & 8.69 & 9.74 & $<0.01$ \\
Error (Test) & 257.01 & 288 & 257.01 & & \\
\multicolumn{5}{c}{ Within-subjects } \\
Group & .446 & 1 & .446 & .178 & .673 \\
Error & 720.797 & 288 & 2.503 & & \\
\hline
\end{tabular}




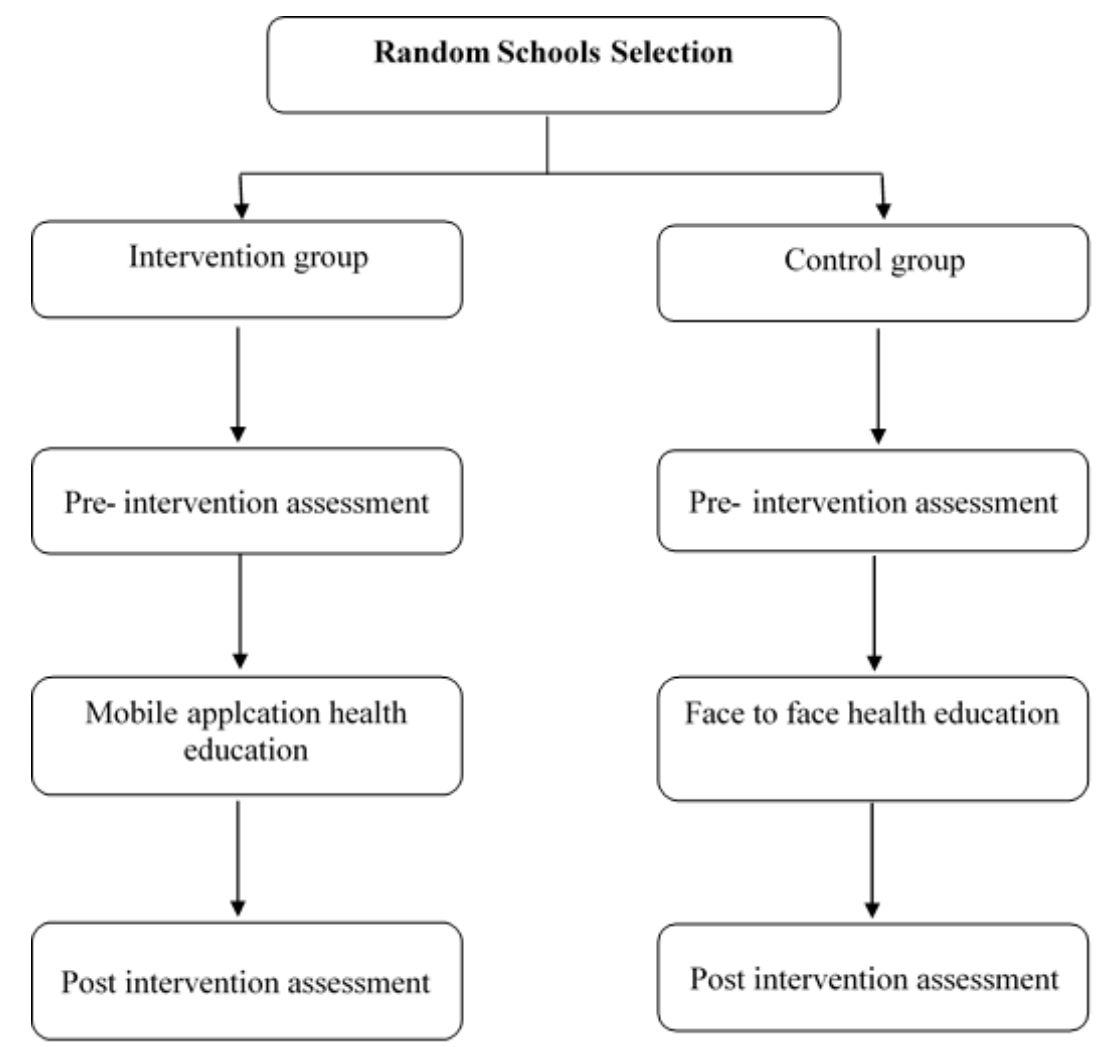

Figure 1

Research Design.
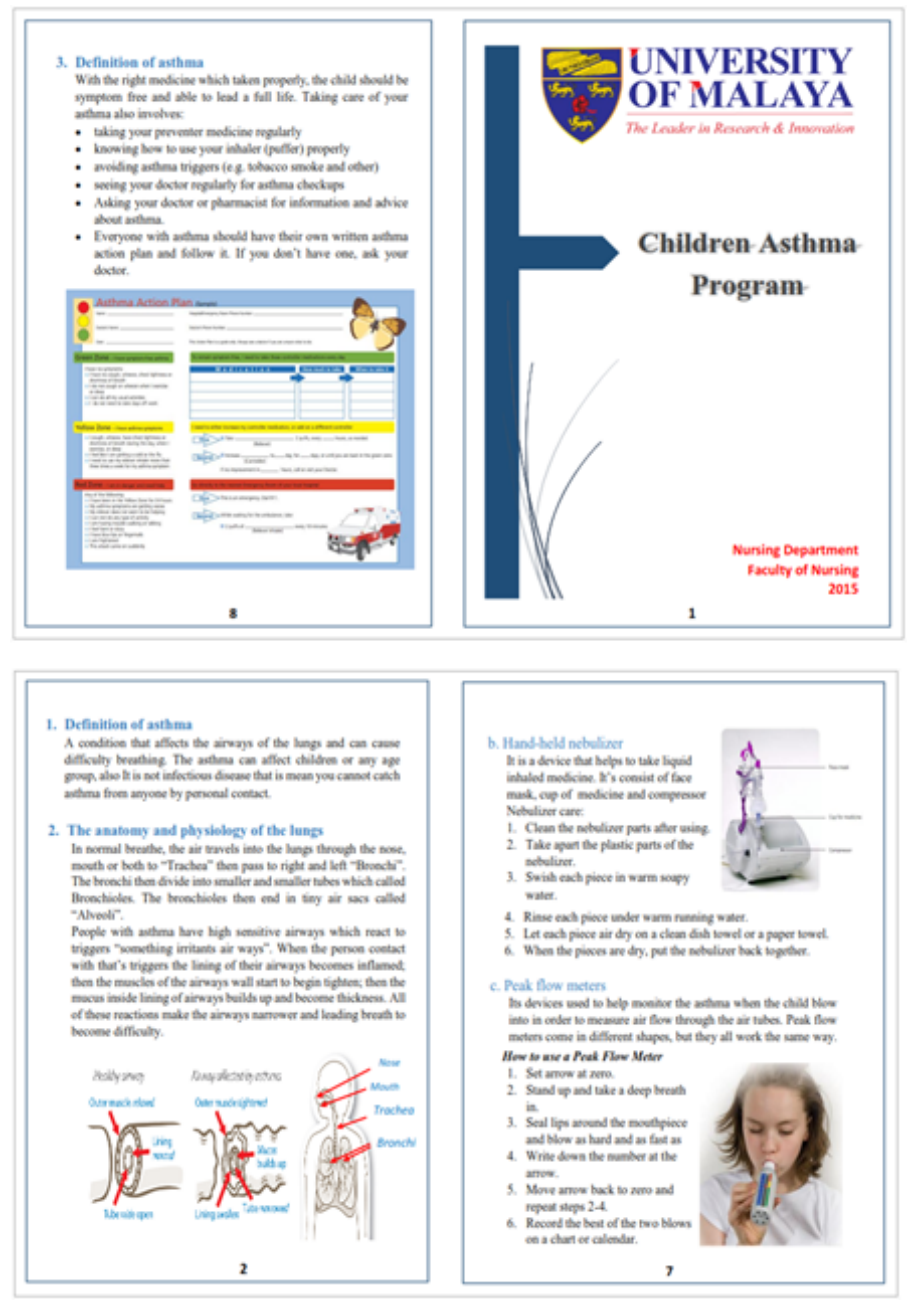


\section{Figure 2}

Children's asthma pamphlet developed by the research team

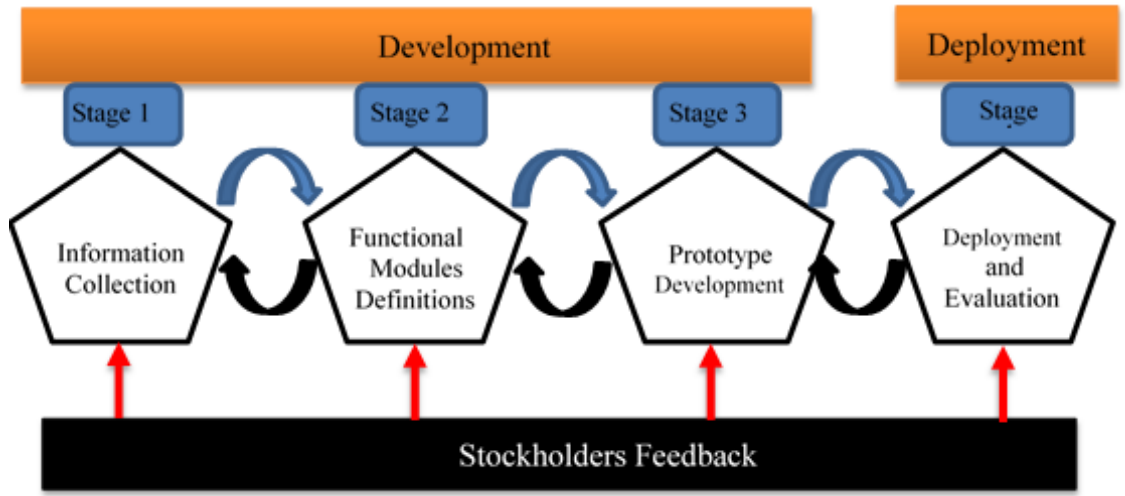

\section{Figure 3}

Design process of asthma mobile app, MemahamiAsma ${ }^{\circledR}$

\section{MemahamiAsma}

Pilih Bahasa

BAHASA MALAYSIA

ENGLISH

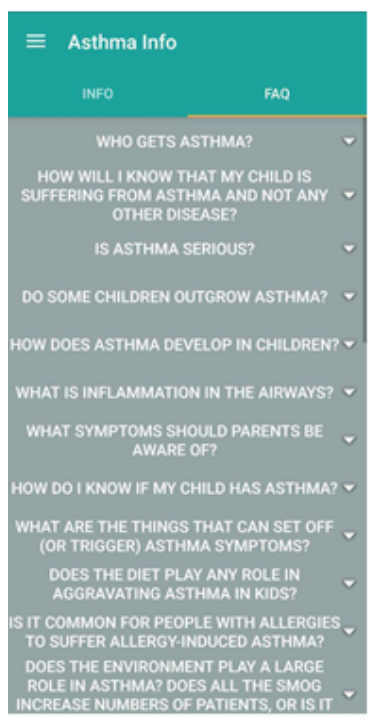

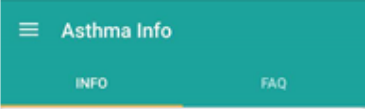

Definition of Asthma

A condition that affects

more infol

The anatomy and physiology In normal breathing, the air Click here for more infol

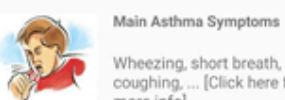
more info!

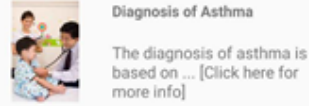
Asthma Triggers Factors and
How to Avoid Them

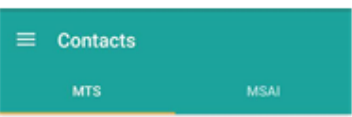

Malaysian Thoracic Society (MTS)

The Malaysian Thoracic Society (MTS) was formed al late 1986 and the oficial navouration was grace

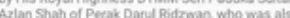
the patron of the society at the first MTS scient te Address

Address
Sutte 2-3, Medical Acadernies of Malaysia, 210 Jalar
Tun Razak 50400 Kusala Lumpur.

Emait

m.thoracicsocietyegmal.com

Phone:

Phone:

Figure 4 
Screenshots of asthma mobile app, MemahamiAsma®

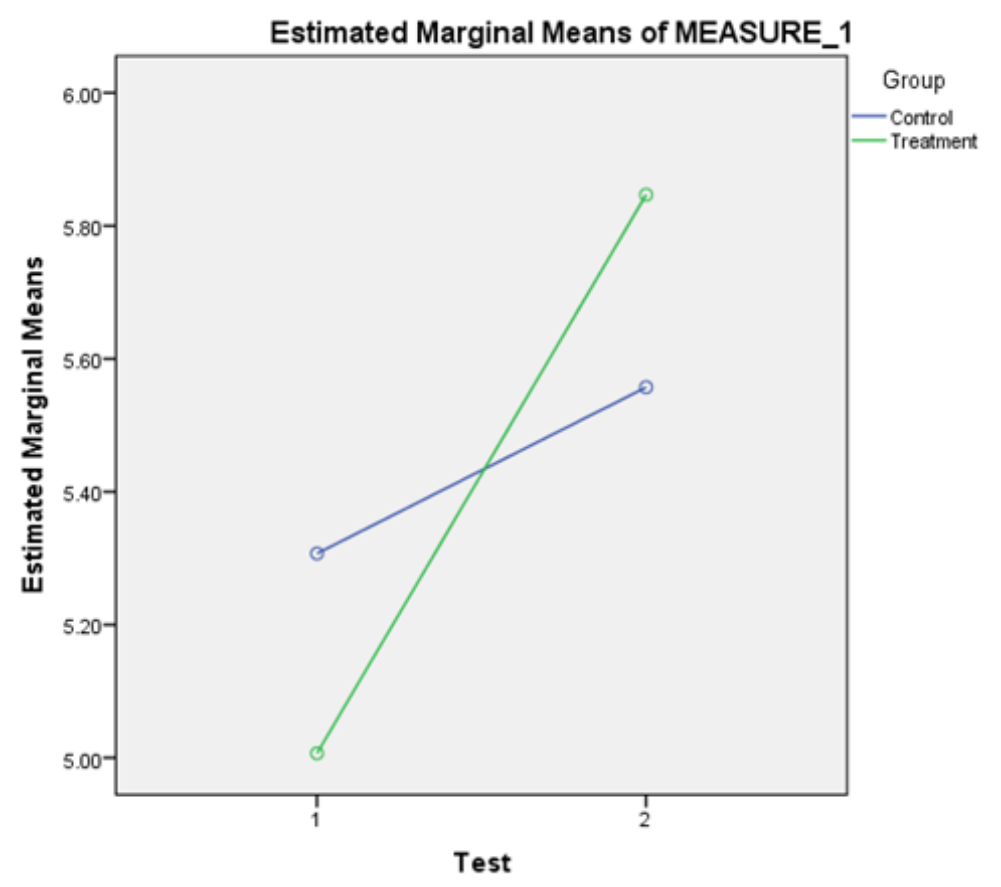

Figure 5

SPANOVA graph plot of control and experimental groups at pre-intervention and post-intervention 